\title{
Acute brain injuries trigger microglia as an additional source of the proteoglycan NG2
}

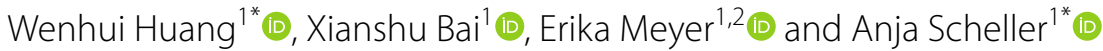

\begin{abstract}
NG2 is a type I transmembrane glycoprotein known as chondroitin sulfate proteoglycan 4 (CSPG4). In the healthy central nervous system, NG2 is exclusively expressed by oligodendrocyte progenitor cells and by vasculature pericytes. A large body of immunohistochemical studies showed that under pathological conditions such as acute brain injuries and experimental autoimmune encephalomyelitis (EAE), a number of activated microglia were NG2 immuno-positive, suggesting NG2 expression in these cells. Alternative explanations for the microglial NG2 labeling consider the biochemical properties of NG2 or the phagocytic activity of activated microglia. Reportedly, the transmembrane NG2 proteoglycan can be cleaved by a variety of proteases to deposit the NG2 ectodomain into the extracellular matrix. The ectodomain, however, could also stick to the microglial surface. Since microglia are phagocytic cells engulfing debris of dying cells, it is difficult to identify a genuine expression of NG2. Recent studies showing (1) pericytes giving rise to microglial after stroke, and (2) immune cells of NG2-EYFP knock-in mice lacking NG2 expression in an EAE model generated doubts for the de novo expression of NG2 in microglia after acute brain injuries. In the current study, we took advantage of three knock-in mouse lines (NG2-CreERT2, CX ${ }_{3} C_{1}$-EGFP and NG2-EYFP) to study NG2 expression indicated by transgenic fluorescent proteins in microglia after IMCAO (transient middle cerebral artery occlusion) or cortical stab wound injury (SWI). We provide strong evidence that NG2-expressing cells, including OPCs and pericytes, did not differentiate into microglia after acute brain injuries, whereas activated microglia did express NG2 in a disease-dependent manner. A subset of microglia continuously activated the NG2 gene at least within the first week after IMCAO, whereas within 3 days after SWI a limited number of microglia at the lesion site transiently expressed NG2. Immunohistochemical studies demonstrated that these microglia with NG2 gene activity also synthesized the NG2 protein, suggesting activated microglia as an additional source of the NG2 proteoglycan after acute brain injuries.
\end{abstract}

Keywords: Microglia, Macrophage, OPCS, Pericytes, NG2, Gliosis, Transgenes, Acute brain injury, MCAO, SWI

\section{Introduction}

Nerve/glia antigen 2 (NG2), encoded by the cspg4 gene (for simplicity we will use NG2 gene instead of cspg4 gene), is a single membrane-spanning proteoglycan with a large extracellular domain, and a short cytoplasmic tail $[43,57]$. In the central nervous system (CNS) of rodents,

\footnotetext{
*Correspondence: wenhui.huang@uks.eu; anja.scheller@uks.eu ${ }^{1}$ Molecular Physiology, Center for Integrative Physiology and Molecular Medicine, University of Saarland, Building 48, 66421 Homburg, Germany Full list of author information is available at the end of the article
}

the earliest NG2 expression was detected in vascular pericytes after embryonic day 10.5 (E10.5) [26, 47]. At E12.5, the NG2 gene starts to get activated in a small population of oligodendrocyte precursor cells (OPCs) in the ventral brain, and subsequently the NG2 protein becomes immuno-detectable in OPCs with increasing proportion from E13.5 to birth [11, 44]. In the postnatal CNS, all OPCs express NG2, therefore they are also termed NG2 glia $[23,42,49]$. Numerous studies using antibody immunostaining and transgenic mouse models revealed that in the healthy CNS, the expression of NG2 is restricted to original author(s) and the source, provide a link to the Creative Commons licence, and indicate if changes were made. The images or other third party material in this article are included in the article's Creative Commons licence, unless indicated otherwise in a credit line to the material. If material is not included in the article's Creative Commons licence and your intended use is not permitted by statutory regulation or exceeds the permitted use, you will need to obtain permission directly from the copyright holder. To view a copy of this licence, visit http://creativecommons.org/licenses/by/4.0/. The Creative Commons Public Domain Dedication waiver (http://creativeco mmons.org/publicdomain/zero/1.0/) applies to the data made available in this article, unless otherwise stated in a credit line to the data. 
OPCs and pericytes but cannot be detected in microglia or astrocytes [10, 11, 22-24, 28, 44].

The large extracellular domain of NG2 contains proteolytic sites near the transmembrane domain, allowing the shedding of the NG2 ectodomain by various proteases such as MMP9, MMP13, MMP14, and the $\alpha$-secretase ADAM10 [51, 57]. Under pathological conditions, glial cells are activated and NG2 expression is greatly enhanced in the injured area, contributing to the formation of the glial scar. Meanwhile, protease level in lesions also increases which could lead to significant deposition of the NG2 ectodomain in the extracellular matrix, therefore blurring the identification of NG2-expressing cells by immunohistochemistry $[1,51,57]$.

Previous studies observed NG2 immunoreactivity in a subset of activated $\mathrm{Iba}^{+}$microglia and/or macrophages (below referred to as microglia for simplicity) in a variety of disease models such as demyelination models induced by lysolecithin or experimental autoimmune encephalomyelitis (EAE) [3, 33, 40, 45], epilepsy model by kainate injection [6], neuroinflammation model by LPS injection $[59,62]$, or the acute injury models transient middle cerebral artery occlusion (tMCAO) and stab wound injury (SWI) $[18,38,52,60]$. However, whether microglia could express NG2 upon injury is still under debate, because previous studies were solely based on NG2 immunoreactivity possibly visualizing the shed ectodomain of NG2 after phagocytosis in the inside or after unspecific deposition on the surface of activated microglia [45, 51, 57]. In addition, although NG2 expression largely increased in the acutely injured area, the reported numbers of NG2 immuno-positive microglia varied from study to study. For example, Tanaka's group showed that in rat brain lesions $\sim 65 \%$ and $~ 80 \%$ of activated microglia displayed NG2 immunoreactivity to a commercial antibody at 7 days post tMCAO and SWI $[38,60]$, respectively. However, with a house-made antibody Hampton et al., detected only $20 \%$ of microglia with NG2 immunoreactivity along the lesion site at 2 days post SWI, and no NG2 immuno-positive microglia at 7 days post injury [18]. These seemingly contradictory results raise doubts that NG2 immuno-positive microglia are NG2-expressing cells in acute brain injury. The situation was further complicated by recent studies suggesting that pericytes (with bona fide expression of NG2) could generate microglia after stroke [46]. In this case, NG2 could be detected as a remnant of a previous cell differentiation event.

On the other hand, the functions of NG2 in diseases were also investigated, though contradictory results appeared among different models. For example, Moransard et al., showed that NG2 detected in macrophages and OPCs was dispensable in an EAE model by using conventional NG2 knockout mice [40]. However, a recent study using NG2-EYFP knock-in (KI) mice in which the expression of EYFP was directly controlled by the endogenous NG2 gene activity demonstrated that NG2 regulated neuroinflammation but was not expressed by immune cells in EAE, suggesting that the contribution of NG2 was derived mainly from OPCs and pericytes [28, 30]. Therefore, it is important to examine whether microglia are activated as sources and/or targets of NG2 in lesions.

In the current study, we used knock-in transgenic mice to investigate the controversial observations in tMCAO and SWI models. We crossbred the myeloid cell-specific GFP-expressing mice $\left(\mathrm{CX}_{3} \mathrm{CR}_{1}\right.$-EGFP $\left.\mathrm{KI}\right)$ to NG2CreERT2 KI mice combined with a Rosa26-tdTomato (Ai14) reporter mouse line, thereby the activation of the NG2 gene in $\mathrm{EGFP}^{+}$cells would be traced in terms of tdTomato ( $\mathrm{tdT}$ ) expression upon tamoxifen induced Cre activity [24, 27, 36]. We also used NG2-EYFP KI mice to further confirm the direct gene activity of NG2 after injury [28]. By combining immunohistochemical analysis and transgenic mouse techniques we were able to show that shortly after acute brain injuries a subset of microglia indeed activated the NG2 locus leading to either EYFP expression or tdT recombination. These results suggest that a subset of microglia indeed activates the NG2 gene, leading to an NG2 transcript as well as a successful translation (NG2 protein). However, the time window of NG2 gene activation in microglia was longer lasting after $\mathrm{tMCAO}$ (at least the first week after occlusion) than SWI (1-3 days).

\section{Materials and methods \\ Ethics statements}

This study was carried out at the University of Saarland in strict accordance with recommendations of European and German guidelines for the welfare of experimental animals. Animal experiments were approved by Saarland state's "Landesamt für Gesundheit und Verbraucherschutz" in Saarbrücken/Germany (animal license numbers: 71/2010, 65/2013, 36/2016).

\section{Animals}

Mouse breeding and animal experiments were performed in the animal facilities of the University of Saarland. In this study only heterozygous adult mice (2-4 months old) were used to prevent knockin out alleles. Inducible Cre DNA recombinase knock-in mice NG2-CreERT2 were always used in combination with floxed reporter mice $($ TgH $($ ROSA26-CAG-fl-stop-sl-tdTomato $)=$ Rosa26$\mathrm{tdT}$ ) to show successful recombination (termed NG2CreERT2xRosa26-tdT mice) [24, 37]. To visualize microglia, the knock-in mouse line $\mathrm{CX}_{3} \mathrm{CR}_{1}$-EGFP was used $\left(\mathrm{TgH}\left(\mathrm{CX}_{3} \mathrm{CR}_{1}-\mathrm{EGFP}\right)=\mathrm{CXCR}^{\mathrm{EGFP}}\right)$ [27]. 
NG2-CreERT2xRosa26-tdT mice were crossed to $\mathrm{CX}_{3} \mathrm{CR}_{1}$-EGFP mice to generate triple transgenic mice

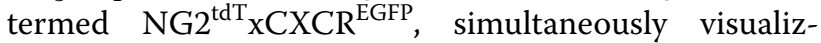
ing NG2-expressing cells and microglia upon tamoxifen administration. For visualization of NG2-expressing cells, the knock-in mouse line NG2-EYFP was analyzed [28].

\section{Transient middle cerebral artery occlusion}

The mice were anesthetized with a mixture of $2 \%$ isoflurane and $47.5 \% \mathrm{O}_{2}$ and $47.5 \% \mathrm{~N}_{2} \mathrm{O}$ using Harvard Apparatus equipment. Focal cerebral ischemia was induced according to the Koizumi method of middle cerebral artery occlusion (MCAO) [31]. In short, the left common carotid artery (CCA) and the external carotid artery (ECA) were permanently ligated with silk sutures. A silicone-coated filament (Doccol Corp, CA) was introduced through an arteriotomy and advanced into the right internal carotid artery (ICA) until mild resistance was felt, indicating the filament reached the origin of the MCA to occlude the blood flow. After 15 min occlusion the filament was withdrawn and a suture was made around the CCA, to prevent back flow through the arteriotomy.

Mouse body temperature was monitored throughout surgery, occlusion and reperfusion using a rectal thermometer and maintained between 36.5 and $37.5{ }^{\circ} \mathrm{C}$ by an adjustable heat plate. After recovery from anesthesia, the mice were kept in their cages with free access to food and water. For three consecutive days the mice received $0.5 \mathrm{~mL}$ subcutaneous injection of saline as fluid replacement and intraperitoneal buprenorphine $(0.01 \mu \mathrm{g} / 30 \mathrm{~g}$ body weight, Temgesic, Essex Pharma, Muenchen, Germany) for pain relief. Mice were evaluated for neurological deficits $2 \mathrm{~h}$ after the surgery as describe previously [38]. Only mice that developed obvious neurological deficits (e.g. consistently circling to the paretic side or showing reduced resistance to lateral push) were used for the following experiments. In total 27 mice were used for the tMCAO operation, in which five mice died (18.5\%) before the end point of the experiment and two mice (7.4\%) did not develop obvious neurological deficits.

\section{Cortical stab wound injury model}

Stab wound injury (SWI) was performed in anesthetized mice (ketamine (Ketavet ${ }^{\circledR}$, Pfizer, Germany)/xylazine (Rumpon $^{\circledR}$, Bayer Healthcare, Germany) in $0.9 \% \mathrm{NaCl}$ (140 mg/10 mg per $1 \mathrm{~kg}$ body weight)). The skull was thinned with dental drill laterally $1.5 \mathrm{~mm}$ and longitudinally $2 \mathrm{~mm}$ from Bregma, followed by a $1 \mathrm{~mm}$ deep stab wound made with a scalpel [19].

After SWI the wound was closed and Buprenorphine (0.01 $\mu \mathrm{g} / 30 \mathrm{~g}$ body weight, Temgesic, Essex Pharma, Muenchen, Germany) was injected for anti-pain treatment. In total 17 mice were used for the SWI model and all mice survived after the surgery till the end point of the experiment.

\section{TTC staining and measurement of the ischemic area}

Mice were euthanized and decapitated $24 \mathrm{~h}$ after the MCAO operation. Brains were dissected and cut into $2 \mathrm{~mm}$ coronal sections. Brain sections were incubated in 2\% TTC (2,3,5-triphenyltetrazolium chloride) (Sigma, St. Louis, MO, USA) dissolved in PBS for $10 \mathrm{~min}$ at $37^{\circ} \mathrm{C}$. After washing by $1 \times \mathrm{PBS}$, the brain sections were fixed in $4 \%$ PFA for $2 \mathrm{~h}$. The images of stained sections were captured under a stereo-microscope (Stemi 2000-C, Zeiss, Göttingen, Germany) equipped with a digital camera (AxioCam ERc 5s, Zeiss, Göttingen, Germany). The ischemic area was determined by measuring the regions that were not stained by TTC using ZEN software (Blue Edition, Zeiss, Oberkochen, Germany).

\section{Immunohistochemistry}

Mouse perfusion, tissue fixation and vibratome slice preparation $(40 \mu \mathrm{m})$ was performed as described previously $[2,24]$. The following primary antibodies were used: polyclonal goat: anti-GFP (1:1000, Rockland, Cat.: 600101215) and anti-Iba1 (1:1000, Abcam, Cat.: ab5076); polyclonal chicken anti-GFP (1:1000, Invitrogen, Cat.: A10262); polyclonal rabbit: anti-NG2 (the extracellular domain) (1:500, Millipore, Cat.: ab5320), anti-Iba1 (1:1000, Wako, Cat.: 01919741), monoclonal rat antiNG2 (AN2, the extracellular domain) (1:50, gift from Dr. Jacqueline Trotter) [41]. Secondary antibodies from donkey (Alexa488-conjugated anti-chicken, Alexa555/647conjugated anti-rabbit, Alexa488/647-conjugated anti-goat (all 1:2000)) were from invitrogen, Grand Island NY, USA. Donkey Cy5-conjugated anti-rat IgG (1:500) antibody was purchased from Dianova, Hamburg, Germany. 4',6-Diamidino-2-phenylindole (DAPI) $(0.025 \mu \mathrm{g} /$ $\mathrm{ml}$ final concentration, from AppliChem, Darmstadt, Germany) was added to the secondary antibody dilutions for nuclear staining.

\section{Tamoxifen-induced gene recombination}

Tamoxifen solution was prepared as previously described [23]. To induce reporter expression in $\mathrm{NG}^{\mathrm{tdT}} \mathrm{xCXCR}^{\mathrm{EGFP}}$ mice, tamoxifen was intraperitoneally injected $(10 \mu \mathrm{g} / \mathrm{ml}$, $100 \mu \mathrm{l} / 10 \mathrm{~g}$ body weight) to mice once per day for three consecutive days according to described experiments in each figure.

\section{Microscopic analysis and quantification}

Epifluorescent images were collected by a fully automated slide scanner (AxioScan.Z1, Zeiss, Jena, Germany) equipped with an LED Light Source (Colibri 7, Zeiss, 


\section{(See figure on next page.)}

Fig. 1 Continuous NG2 gene activation in a subset of microglia after tMCAO. a Overview of transgene structures of mouse lines used in tMCAO model. CX ${ }_{3} C R_{1}$-EGFP, NG2-CreERT2, and Rosa26-tdTomato mice were crossbred to generate a triple transgenic mouse termed $N G 2^{\text {tdT }} \times C X C R^{E G F P}$. b NG $2^{\text {tdT }} X C X C R^{E G F P}$ mice were used for tMCAO. Subsequently injured mice were injected with tamoxifen (TAM) for three consecutive days from 0 to 2 days post injury (0-2 dpi), 2-4 dpi, or 4-6 dpi, and were analyzed at 7, 9, and 11 dpi respectively (7 days after the first day of TAM injection). c Overview of a coronal brain section of a NG2 ${ }^{\text {td }}$ XCXCR ${ }^{\text {EGFP }}$ mouse treated with TAM at $2-4$ dpi after tMCAO. EGFP ${ }^{+}$microglia were drastically activated in the infarct-related area of the brain. $\mathbf{d}$ and $\mathbf{e}$ Magnified views from white boxes in $\mathbf{c}$ showing that in general the expression of EGFP (triangles) and tdT (open arrowheads) were found in distinct cell populations. However, $\mathrm{tdT}^{+} \mathrm{EGFP}^{+}$cells (arrowheads) could also be observed. White boxes in $\mathbf{d}$ and $\mathbf{e}$ highlighted the morphology of $\mathrm{tdT}^{+} \mathrm{EGFP}^{+}$cells representing activated microglia. $\mathbf{f}$ and $\mathbf{g}$ Quantification of tdT ${ }^{+} \mathrm{EGFP}^{+}$ cells in the infarcted striatum (depicted by the dashed line in c) when tamoxifen was injected at different time points, represented as either the numbers of $\mathrm{tdT}^{+} \mathrm{EGFP}^{+}$cells per coronal brain slice $(\mathbf{f})$ or the density of $\mathrm{tdT}^{+} \mathrm{EGFP}^{+}$cells $(\mathbf{g})$. The color coding shows the data points per animal ( $n=3-5$ mice indicated as big circles with 2-6 data points (small ones) per mouse). Scale bars $=1000 \mu \mathrm{m}$ in $\mathbf{c}$, and $50 \mu \mathrm{m}$ in $\mathbf{d}$ and $\mathbf{e}$

Jena, Germany). The appropriate excitation and emission filters (excitation/emission wavelengths in $\mathrm{nm}$ ) were set as: $353 / 465$ (DAPI), 488/509 (green), 548/561 (red), and $650 / 673$ (infrared). A Plan-Apochromat $10 \times / 0.45$ objective for pre-focusing and a Plan-Apochromat $20 \times / 0.8$ objective for fine focus image acquisition was used. Offline image stitching ( $8 \mu \mathrm{m}$ stacks, variance projection) for overviews of brain slices and further analysis was performed using ZEN software (Blue Edition, Zeiss, Oberkochen, Germany).

Confocal images were taken using a laser-scanning microscope (LSM-710, Zeiss) as previously described [23]. Figures presented in this work were modified with Zen 1 software (Black Edition, Zeiss, Oberkochen, Germany).

\section{Statistical analysis}

For the tMCAO model, 2-6 sections per mouse and three to five mice per group were used. For SWI model, 6-15 sections per mouse and at least five mice per group were analyzed. Data are presented as mean \pm SEM of biological replicates (mice). The normal distribution of the data were confirmed by the Shapiro-Wilk test. To compare the number of $\mathrm{tdT}^{+} \mathrm{EGFP}^{+}$cells per slice (Figs. 1f, 4f), and the density of $\mathrm{tdT}^{+} \mathrm{EGFP}^{+}$cells in Fig. 1g, oneway ANOVA with Tukey's post hoc multiple comparisons was performed. The levels of significance were set as " $P<0.05 ; * * 0.01$.

\section{Results}

\section{NG2 was expressed in a subset of microglia after $\mathrm{TMCAO}$}

Previous studies demonstrated the NG2 immunoreactivity in a significant number of microglia within the lesion area after tMCAO. However, those results from immunostaining against NG2 might be attributed to the expression of NG2 in microglia per se, or the shed ectodomain of NG2 after injury. To circumvent the shortcomings of immunohistochemistry for NG2, we took advantages of NG2-CreERT2xRosa26-tdT mice in which NG2-expressing cells could be traced by tdT expression upon tamoxifen administration, and $\mathrm{CX}_{3} \mathrm{CR}_{1}$-EGFP mice in which myeloid cells including microglia and macrophages were visualized by EGFP expression. We crossed NG2-CreERT2xRosa26-tdT mice to $\mathrm{CX}_{3} \mathrm{CR}_{1}$-EGFP mice to generate a new triple transgenic mouse line termed $\mathrm{NG}^{\mathrm{tdT}} \mathrm{xCXCR}^{\mathrm{EGFP}}$, allowing visualization of NG2-expressing cells and microglia simultaneously upon induction of Cre activity by tamoxifen (Fig. 1a).

To determine when, if any, $\mathrm{EGFP}^{+}$cells could turn on NG2 gene after tMCAO, we injected adult $\mathrm{NG}^{\mathrm{tdT}} \mathrm{XCXCR}^{\mathrm{EGFP}}$ mice with tamoxifen at $0-2,2-4$, or 4-6 days post injury (dpi) for three consecutive days and analyzed at 7 days after the first tamoxifen injection (7, 9, and $11 \mathrm{dpi}$, respectively) (Fig. 1b). To increase the viability, animals got $15 \mathrm{~min}$ tMCAO before reperfusion to induce detectable infarction as previously described [48]. Determined by TTC staining, $25 \%$ of the area of coronal brain sections was affected by ischemia $24 \mathrm{~h}$ after the operation (Additional file 1: Fig. S1a-c). After tMCAO, we observed highly activated $\mathrm{EGFP}^{+}$cells in terms of increased fluorescent protein expression and cell density in many regions of the infarcted hemisphere of the brain, such as striatum, thalamus, hippocampus and cortex (Fig. 1c, bright green area, Additional file 1: Fig. S1d, e). In parallel, Cre activity induction generated tdTexpressing cells all over the brain, including those infarctaffected regions (Fig. 1c). Although in the gliosis area the majority of $\mathrm{tdT}^{+}$and EGFP ${ }^{+}$cells still did not overlap, we did detect a small number of $\mathrm{EGFP}^{+}$cells co-expressing tdT whenever Cre activity was induced after tMCAO. Microglia are known to display numerous morphological changes upon stimulation [29]. We noticed that those $\mathrm{tdT}^{+}$EGFP $^{+}$cells also possessed diverse morphologies such as ramified, amoeboid, or round shapes, representing activated microglia and/or macrophages (Figs. 1d, e, $3 \mathrm{~d}$, e) [14, 34]. In contrast, virtually no tdT ${ }^{+} \mathrm{EGFP}^{+}$cells were found in the injured regions when $\mathrm{TMCAO}$ was performed 10 days after tamoxifen administration (Fig. 2), suggesting $\mathrm{tdT}^{+} \mathrm{EGFP}^{+}$cells resulted from acute NG2 


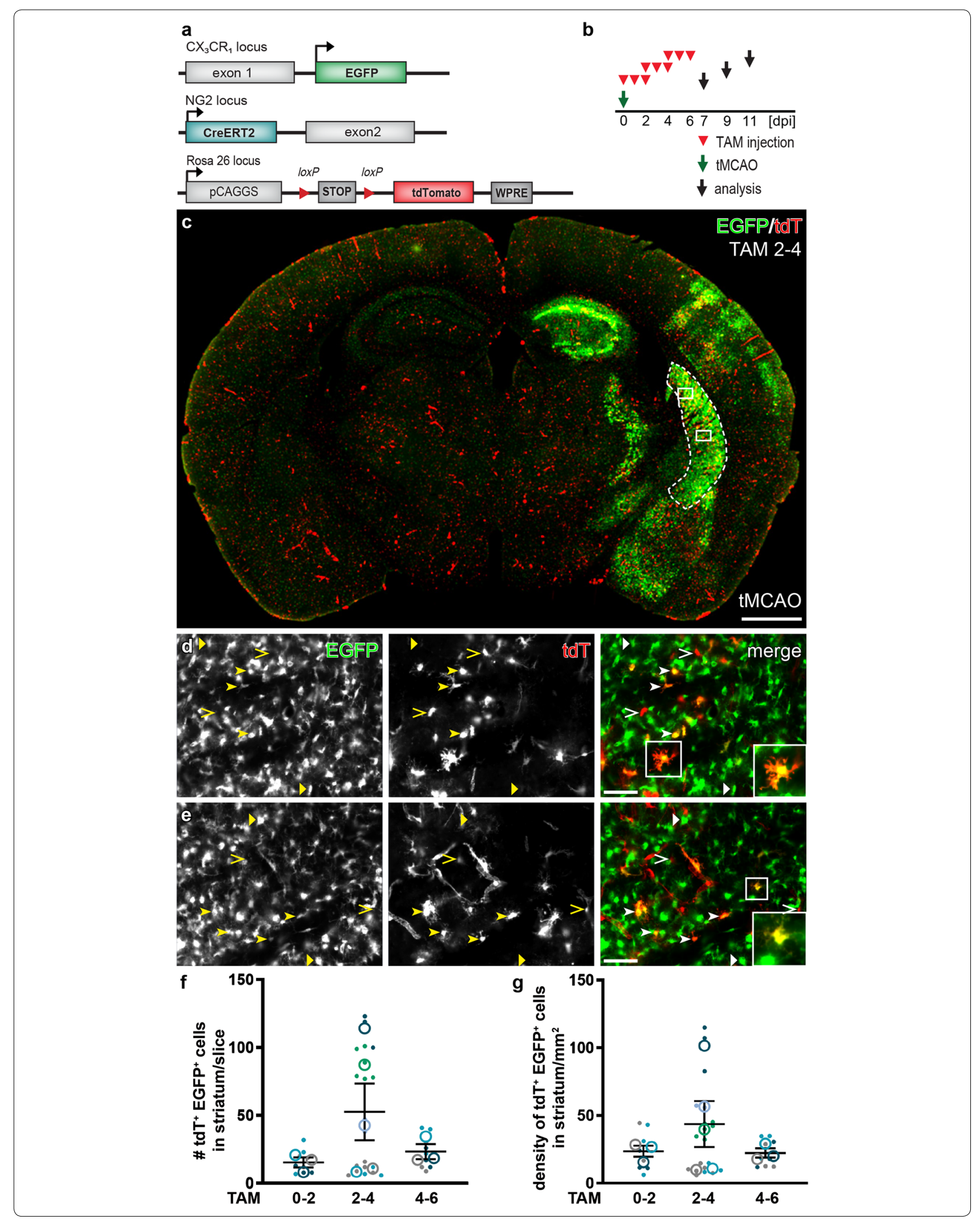




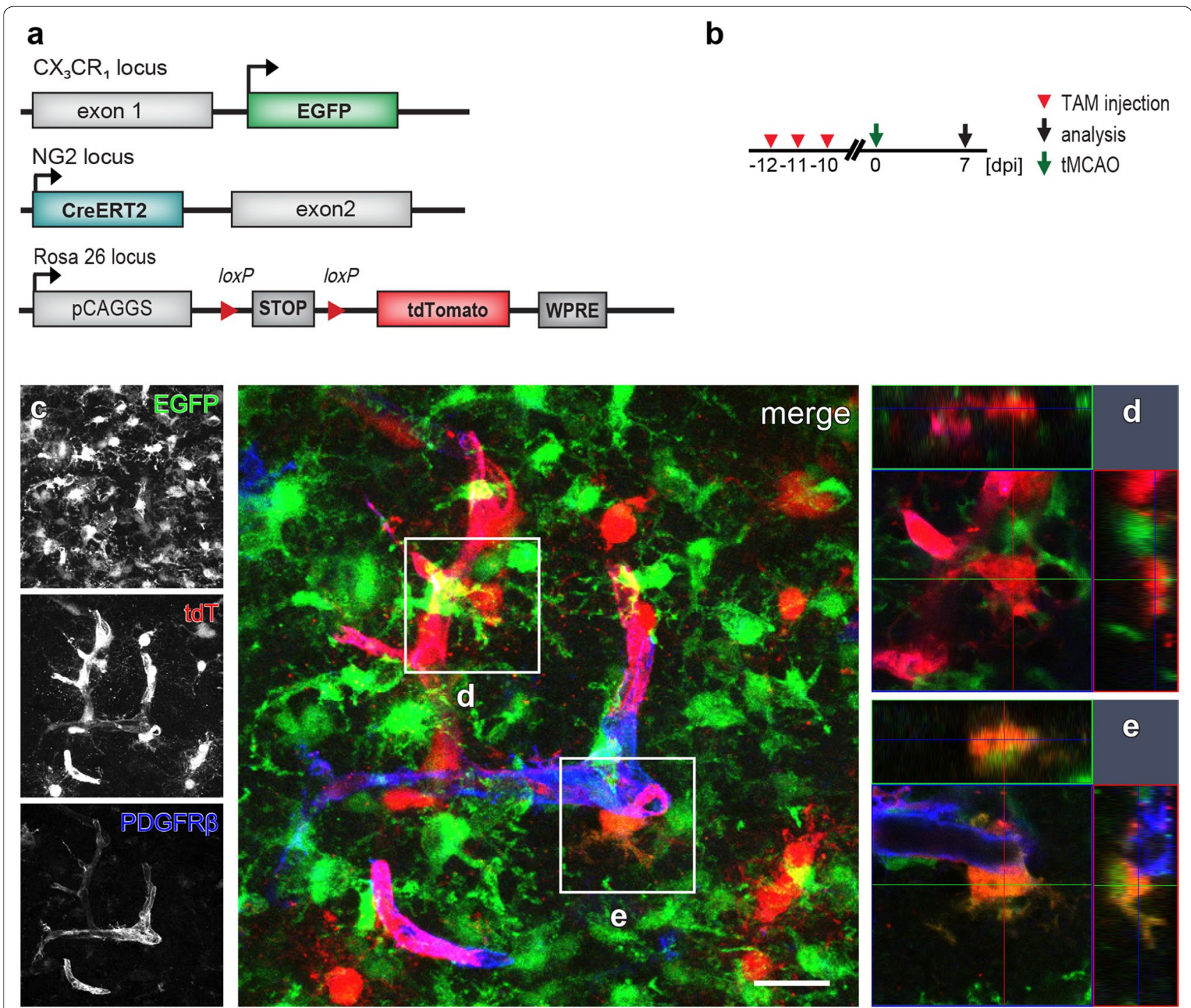

Fig. 2 No differentiation of NG2-expressing cells into microglia after $\mathrm{MMCAO}$. a Scheme of transgene structures of the triple transgenic mouse line $N G 2^{\text {tdT }} \times C X C R^{E G F P}$ used in tMCAO model. $\mathbf{b}$ Experimental plan: $N G 2^{\text {tdT }} \times C X C R^{E G F P}$ mice were occluded (tMCAO) 10 days after the 3-day injection of tamoxifen (TAM) and were analyzed at 7 days post injury (dpi). c- $\mathbf{d}$ Representative confocal images from injured striatum showed that virtually all $\mathrm{tdT}^{+}$cells (including cells in oligodendrocyte lineage and pericytes labeled by PDGFRß) were not co-expressing EGFP, and intermingled cells could be distinguished by the Z-stack images (d, orthogonal view of the corresponding white box in $\mathbf{c}$ ). Very rarely tdT ${ }^{+} \mathrm{EGFP}^{+}$cells ( 2 cells found in 18 brain slices from three mice, 6 slices per mouse) were detected as indicated in e (orthogonal view of the corresponding white box in c). Scale $\mathrm{bar}=20 \mu \mathrm{m}$

gene activity in triggered microglia rather than from the differentiation of recombined NG2-expressing cells. We therefore conclude that a small population of microglia activated the NG2 gene after $\mathrm{TMCAO}$.

To investigate the dynamic activation of the NG2 gene in microglia after tMCAO, we quantified the numbers of $\mathrm{tdT}^{+} \mathrm{EGFP}^{+}$cells found in the ipsilateral striatum, the most affected region, from different time points of tamoxifen treatment. When Cre activity was induced at
0-2 dpi, $15 \pm 7 \mathrm{tdT}^{+} \mathrm{EGFP}^{+}$cells could be found in the striatum per brain slice. The number of $\mathrm{tdT}^{+} \mathrm{EGFP}^{+}$cells increased to $50 \pm 21$ per slice and then fell back to $23 \pm 6$ per slice when tamoxifen was injected at 2-4 and 4-6 dpi, respectively (Fig. 1f). The corresponding density of those detected $\mathrm{tdT}^{+} \mathrm{EGFP}^{+}$cells also showed a similar trend along the time line of tamoxifen administration $(24 \pm 4$, $43 \pm 17$, and $22 \pm 3$ cells $/ \mathrm{mm}^{2}$ from striatum treated with tamoxifen at 0-2, 2-4 and 4-6 dpi, respectively) (Fig. 1g, 


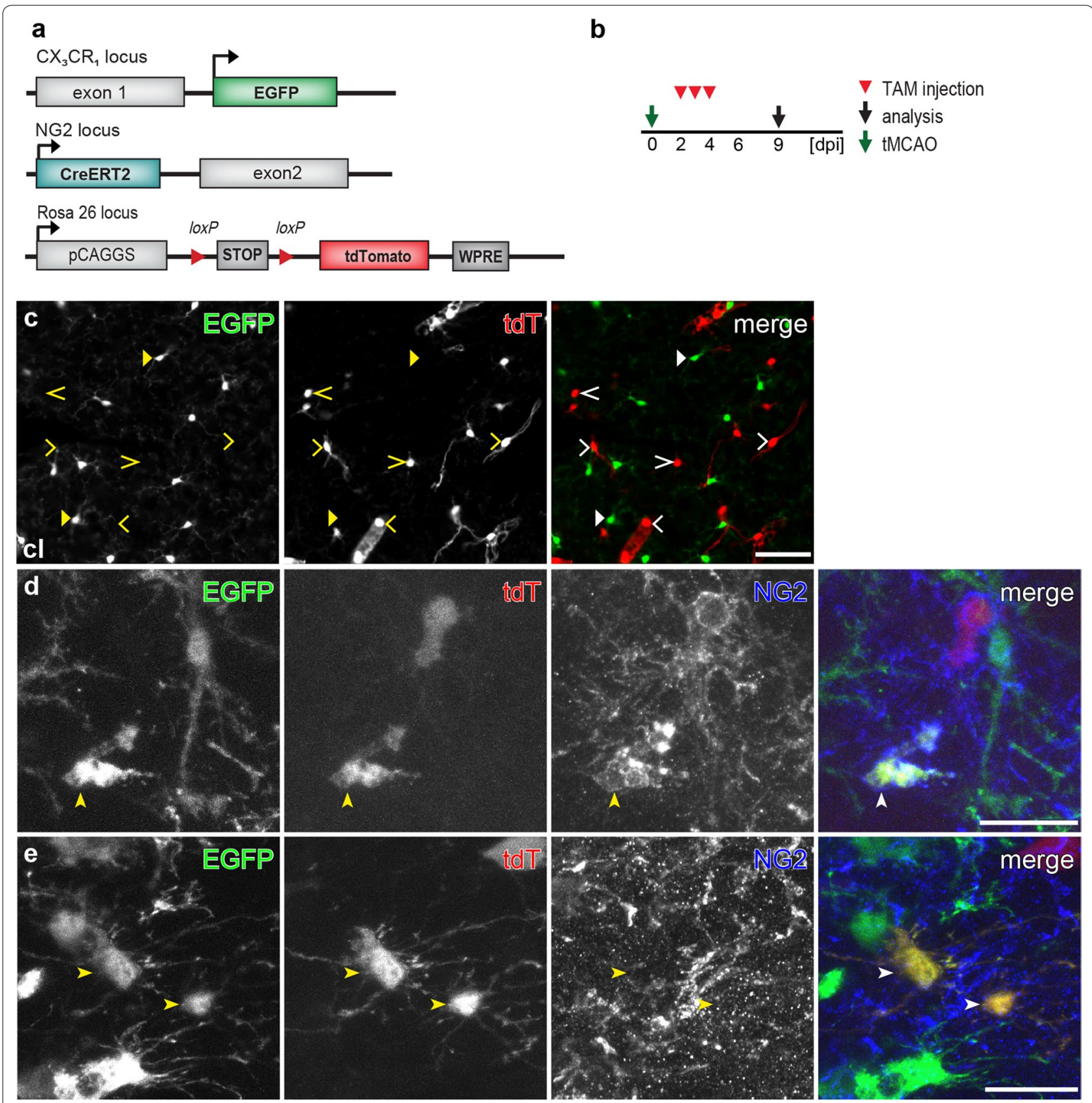

Fig. 3 NG2 protein expression in some microglia after tMCAO. a Overview of transgene structures of the triple transgenic mouse line $N G 2^{\text {tdT }} \times C X C R^{\text {EGFP }}$ used in $\mathrm{TMCAO}$ model. b Experimental plan: NG2 ${ }^{\text {tdT }} \times C X C R^{E G F P}$ mice were injected with tamoxifen (TAM) for three consecutive days from 2 to 4 days post injury (dpi) and were analyzed at 9 dpi in the tMCAO model. c Micrographs showing EGFP ${ }^{+}$cells and tdT ${ }^{+}$cells never overlapped in the contralateral hemisphere. $\mathrm{TdT}^{+}$cells displayed either morphology of oligodendrocyte lineage cells (open arrowheads) or vascular pericytes (open triangle). $\mathbf{d}$ and $\mathbf{e}$ Confocal images in the infarct region with $\mathrm{tdT}^{+} \mathrm{EGFP}^{+}$cells immuno-positive (d) or immuno-negative (e) for NG2. Scale bars $=50 \mu \mathrm{m}$ in $\mathbf{c}, 20 \mu \mathrm{m}$ in $\mathbf{d}$ and $\mathbf{e}$

Additional file 1: Fig. S1f, g). In the contralateral hemisphere, no tdT ${ }^{+}$cells with EGFP expression were found, indicating microglial NG2 activity was triggered by the injury (Fig. 3a-c). Therefore, activation of the NG2 gene occurred constantly in a small population of microglia after tMCAO. Furthermore, immunohistochemical experiments with antibodies against the extracellular domain of NG2 demonstrated that many of those $\mathrm{tdT}^{+}$ 


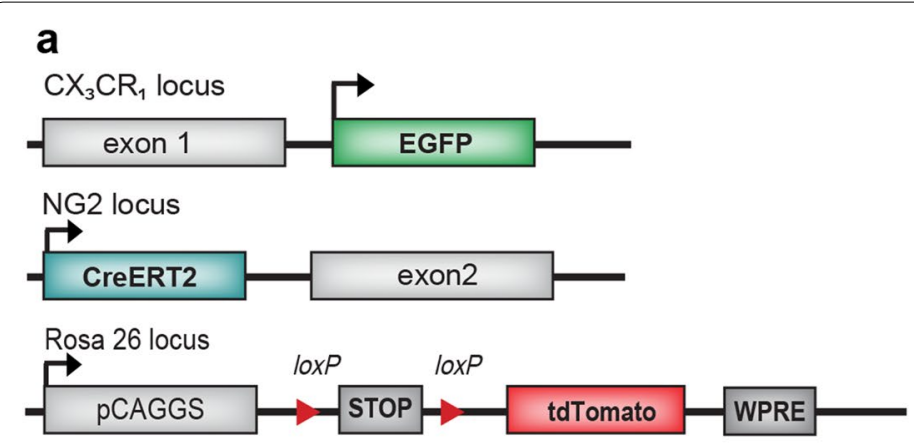

b
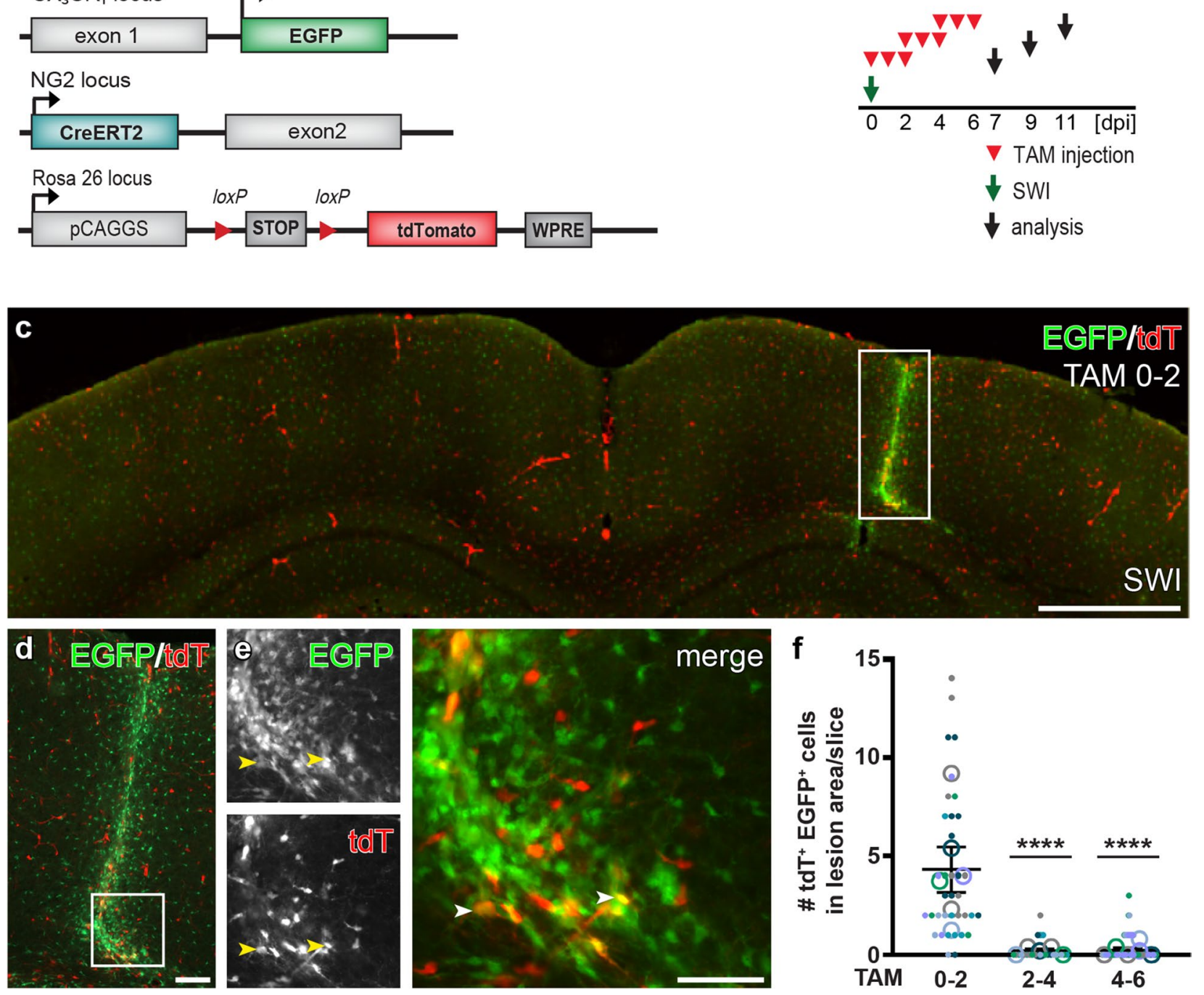

Fig. 4 Transient activation of the NG2 gene upon SWI in a subset of microglia. a Schematic of transgene structures of NG2 $2^{\mathrm{tdT}} \times C X C R^{\mathrm{EGFP}}$ mice used $^{\mathrm{a}}$ in SWI model. b Experimental plan: Subsequently after SWI, injured NG2 ${ }^{\text {tdT }}$ XCXCR ${ }^{\text {EGFP }}$ mice were injected with tamoxifen (TAM) for three consecutive days from 0 to 2 days post injury (0-2 dpi), 2-4 dpi, or 4-6 dpi, and were analyzed at 7, 9, and 11 dpi respectively. c Overview of a coronal brain section of a NG2 ${ }^{\text {tdT }} \times C X C R^{E G F P}$ mouse at 7 dpi treated with TAM at 0-2 dpi. Along the injury site in the cerebral cortex, activation of EGFP ${ }^{+}$microglia were detected in terms of increased cell density and EGFP expression. $\mathbf{d}$ Injured area (white box in c) shown in higher magnification. e Magnified view from white box in d showing a few $\mathrm{tdT}^{+} \mathrm{EGFP}^{+}$cells (arrowheads) at the lesion site. $\mathbf{f}$ Numbers of $\mathrm{tdT}^{+} \mathrm{EGFP}^{+}$cells found per coronal brain slice when tamoxifen was injected at different time points after SWI. The color coding shows the data points per animal $(n=3-5$ mice indicated as big circles with 5-15 data points (small ones) per mouse). Scale bars $=1000 \mu \mathrm{m}$ in $\mathbf{c}, 100 \mu \mathrm{m}$ in $\mathbf{d}$, and $50 \mu \mathrm{m}$ in $\mathbf{e}$

$\mathrm{EGFP}^{+}$cells were immuno-positive for NG2 (Fig. 3d, e), suggesting that those $\mathrm{tdT}^{+}$microglia not only activated NG2 promoter but also synthesized NG2 protein.

Taken together, our current results from $\mathrm{NG}^{\mathrm{tdT}} \mathrm{xCXCR}{ }^{\mathrm{EGFP}}$ mice provide strong evidence for an acute NG2 expression in a subset of microglia in the infarct-affected regions, at least within the first week after $\mathrm{tMCAO}$.

\section{SWI leads to the transient activation of the NG2 gene in a subset of microglia}

Unlike tMCAO, SWI is type of acute brain injury with direct bleeding into the parenchyma. To investigate whether microglia also acquire a similar dynamic activation of the NG2 gene after cortical SWI, we used the $\mathrm{NG}^{\mathrm{tdT}} \mathrm{XCXCR}^{\mathrm{EGFP}}$ mice with the same tamoxifen induction protocols as used in the tMCAO model (Fig. 4a, b). 
(See figure on next page.)

Fig. 5 NG2 gene-activated microglia with NG2 protein expression within short time after SWI. a Overview of transgene structures of NG2 ${ }^{\text {tdT }} \times C X C R^{\text {EGFP }}$ mice used in SWI model. $\mathbf{b}$ Experimental design: After SWI, NG2 ${ }^{\text {tdT }} \times C X C R^{E G F P}$ mice were injected with TAM from 0 to 2 dpi, and analyzed at 3, 7, or 28 dpi. c-f Confocal images showing NG2 immunoreactivity in tdT ${ }^{+}$, EGFP+ ${ }^{+}$cells at the lesion site at 3 dpi (c, d), and 7 dpi (e, f). EGFP (triangles) and tdT (open arrowheads) were mostly expressed in different cell types, with exceptions of a few tdT ${ }^{+}$EGFP $^{+}$cells detected at the lesion site (arrowheads). The immunoreactivity to NG2 was detected in some tdT ${ }^{+}$EGFP $^{+}$cells (arrows indicate the NG2 positive processes) at 3 dpi (d, magnifying the white box in c) but undetectable at $7 \mathrm{dpi}$ (f, magnifying the white box in $\mathbf{e}$ ), whereas most cells expressing only tdT (arrowheads) were always NG2 immunopositive with some exceptions indicating their differentiation into mature oligodendrocytes. $\mathbf{g}$ Confocal images showing a tdT $^{+}$EGFP $^{+}$cell found at $28 \mathrm{dpi}$, with the orthogonal view (right image). Scale bars $=20 \mu \mathrm{m}$ in $\mathbf{c}, \mathbf{e}, \mathbf{f}$, and $10 \mu \mathrm{m}$ in $\mathbf{d}, \mathbf{g}$

SWI triggered a substantial activation of microglia along the lesion site (Fig. 4c, d, bright green area). Tamoxifen treatment could always induce recombination of the tdT reporter over the whole brain including the injured area. Like in the tMCAO model, no tdT expression was detected in $\mathrm{EGFP}^{+}$cells outside the injured area. However, we could always observe a small number of $\mathrm{tdT}^{+}$ $\mathrm{EGFP}^{+}$cells ( $\sim 5$ cells per brain slice) at the lesion site (within $300 \mu \mathrm{m}$ of the stab wound) when tamoxifen was administered at $0-2$ dpi (Figs. 4e, f, 5). The number of $\mathrm{tdT}^{+} \mathrm{EGFP}^{+}$cells quickly decreased to less than $\sim 1$ cell/ per brain slice when tamoxifen was given later at $2-4$ or 4-6 dpi (Fig. 4f). In addition, without tamoxifen we only observed very sporadic $\operatorname{td}^{+}$cells even at the lesion site that never co-expressed EGFP, indicating $\mathrm{tdT}^{+} \mathrm{EGFP}^{+}$ cells were not resulted from injury-induced spontaneous recombination (Additional file 1: Fig. S2). When Cre activity was induced 70 days before SWI, we detected a number of $\operatorname{tdT}^{+}$cells without any EGFP expression at the lesion site at 3 or $14 \mathrm{dpi}$, suggesting that $\mathrm{NG}^{+}$cells did not differentiate into microglia (Additional file 1: Fig. S2). Notably, whenever tamoxifen was administered, we could detect cell debris of $\mathrm{tdT}^{+}$cells being phagocytosed by EGFP ${ }^{+}$microglia after SWI (Additional file 1: Fig. S3, $\mathrm{tdT}^{+}$particles wrapped by EGFP ${ }^{+}$cells), which could be easily distinguished from the $\mathrm{EGFP}^{+}$cells co-expressing tdT by their morphology. Therefore, the present results suggest that a small number of microglia at the lesion site transiently activated their NG2 gene shortly after SWI.

To determine whether those NG2 gene-active microglia also produce the NG2 protein after SWI, we induced Cre activity at $0-2$ dpi and performed immunohistochemistry for NG2 at 3, 7 or 28 dpi (Fig. 5a, b). In line with the results from the study for dynamic activation of NG2 gene, we only detected NG2 immunoreactivity on $\mathrm{tdT}^{+} \mathrm{EGFP}^{+}$ cells at $3 \mathrm{dpi}$, but never at 7 or $28 \mathrm{dpi}$ (Fig. $5 \mathrm{c}-\mathrm{g}$ ). To further confirm the NG2 expression in activated microglia after SWI, we took advantage of NG2-EYFP knock-in mice, which demonstrate endogenous NG2 gene activation as EYFP expression. We performed immunostaining against Iba1 (a marker for microglia) and NG2 at 3, 4, or 5 day after SWI to seek microglia with EYFP and NG2 expression (Fig. 6a, b). At 3 dpi, we detected few $\mathrm{NG}^{+}$
$\mathrm{Iba}^{+}$cells expressing EYFP at the lesion site (Fig. $6 \mathrm{c}, \mathrm{d}$, arrowheads). These $\mathrm{EYFP}^{+} \mathrm{Ibal}^{+}$cells showed amoeboid or round shape, representing activated microglia or macrophage-like morphology. In addition, we also observed $\mathrm{NG}^{+} \mathrm{Iba}^{+}$cells without EYFP expression (Fig. 6d, open arrowheads), possibly due to the degradation of EYFP after the transient activation of the NG2 gene. At 4 dpi, it became rather difficult to find $\mathrm{Iba}^{+}$cells co-expressing EYFP (Fig. 6e). One day later (5 dpi) no overlay between EYFP-expressing cells and Iba1 immunoreactivity could be observed anymore (Fig. 6f). Regarding the half-life of jelly fish proteins (EGFP: 26 h) [9], current studies of NG2EYFP mice suggested a time window of 1-3 days for the NG2 promoter activation in microglia after SWI, in line with results from $\mathrm{NG}^{\mathrm{tdT}} \mathrm{xCXCR^{ \textrm {EGFP } }}$ mice.

\section{Discussion}

Several previous studies detected NG2 immunoreactivity on microglia or macrophages in a variety of disease models. However, the existence of NG2-expressing microglia was still debated. Main reasons were alternative explanations inherent to the biochemistry of NG2 itself and its cell biology. Both of which are difficult to be addressed by immunohistochemistry only: (1) the shed ectodomain of NG2 and a possible deposition at the lesion site, (2) differentiation of pericytes into microglia with residual NG2 protein, and (3) microglial phagocytotic activity of dying $\mathrm{NG}^{+}$cells $[45,46,51,57]$. Indeed, microglia could engulf myelin debris upon injury $[5,13,50,58]$. Furthermore, a recent study using NG2-EYFP mice found no NG2-expressing immune cells in an EAE model, raising doubts for NG2-expression by microglia in other disease models [30]. In the present study, we took advantage of the direct fluorescent protein expression in the triple transgenic mouse line $\mathrm{NG}^{\mathrm{td} T} \mathrm{xCXCR}^{\mathrm{EGFP}}$ to circumvent the shortcomings of immunohistochemical studies of NG2 expression in microglia, by temporally controlling the induction of Cre DNA recombinase activity.

When Cre activity was induced before tMCAO or SWI, we virtually never detected $\mathrm{tdT}^{+} \mathrm{EGFP}^{+}$cells, indicating that NG2-expressing cells, including NG2 glia and pericytes, do not differentiate into microglia. Our results were 


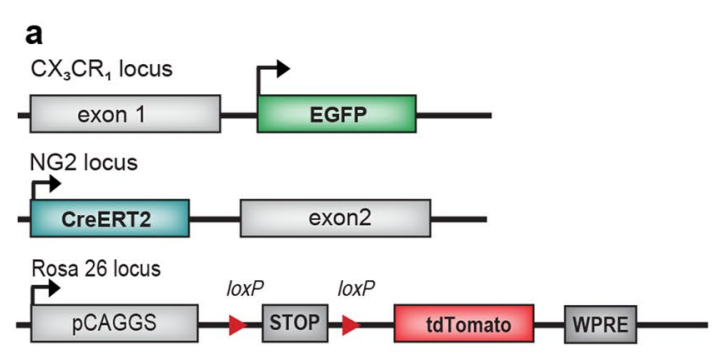

b

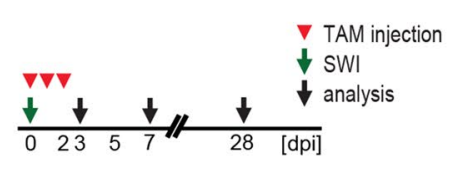

힘
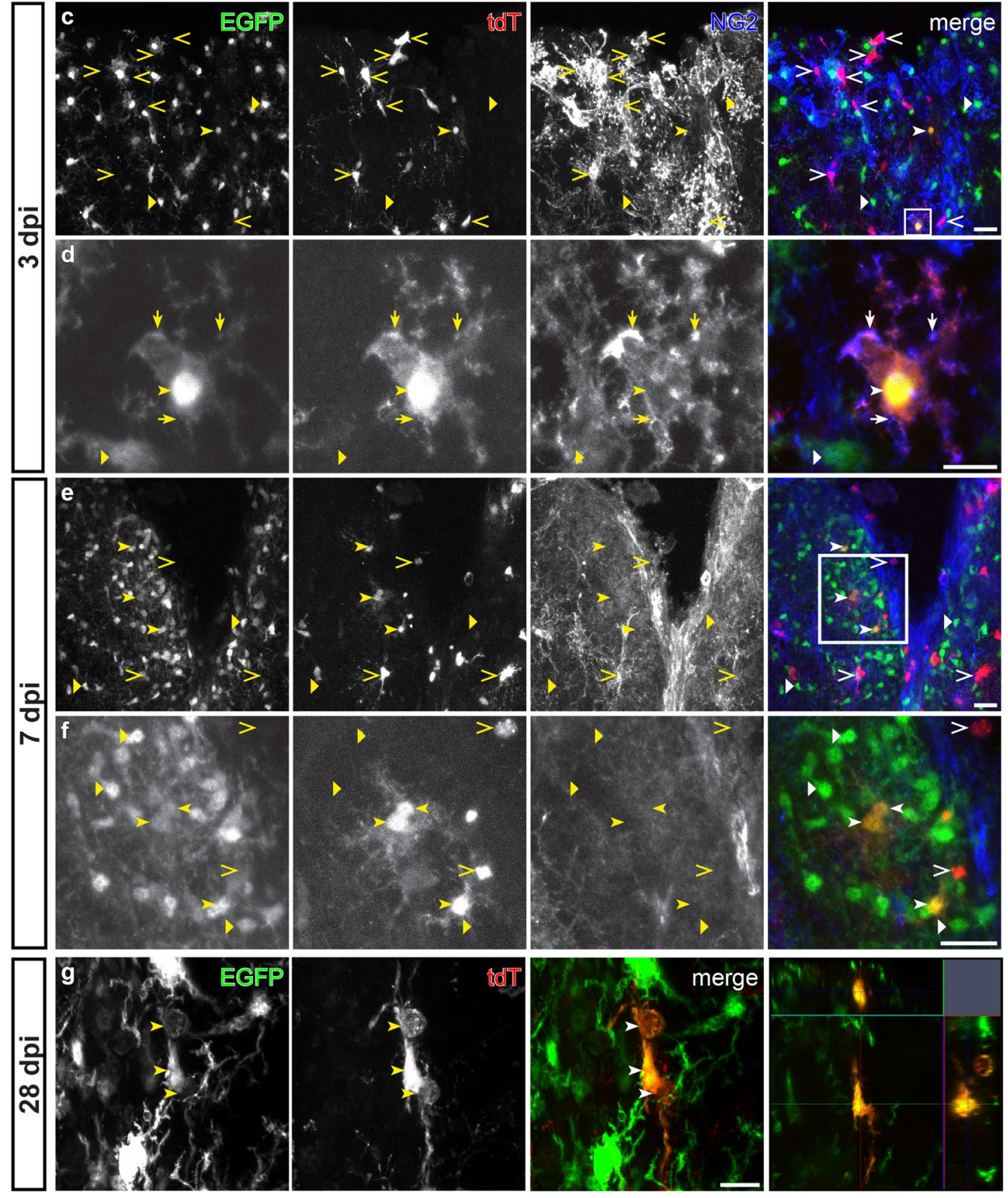


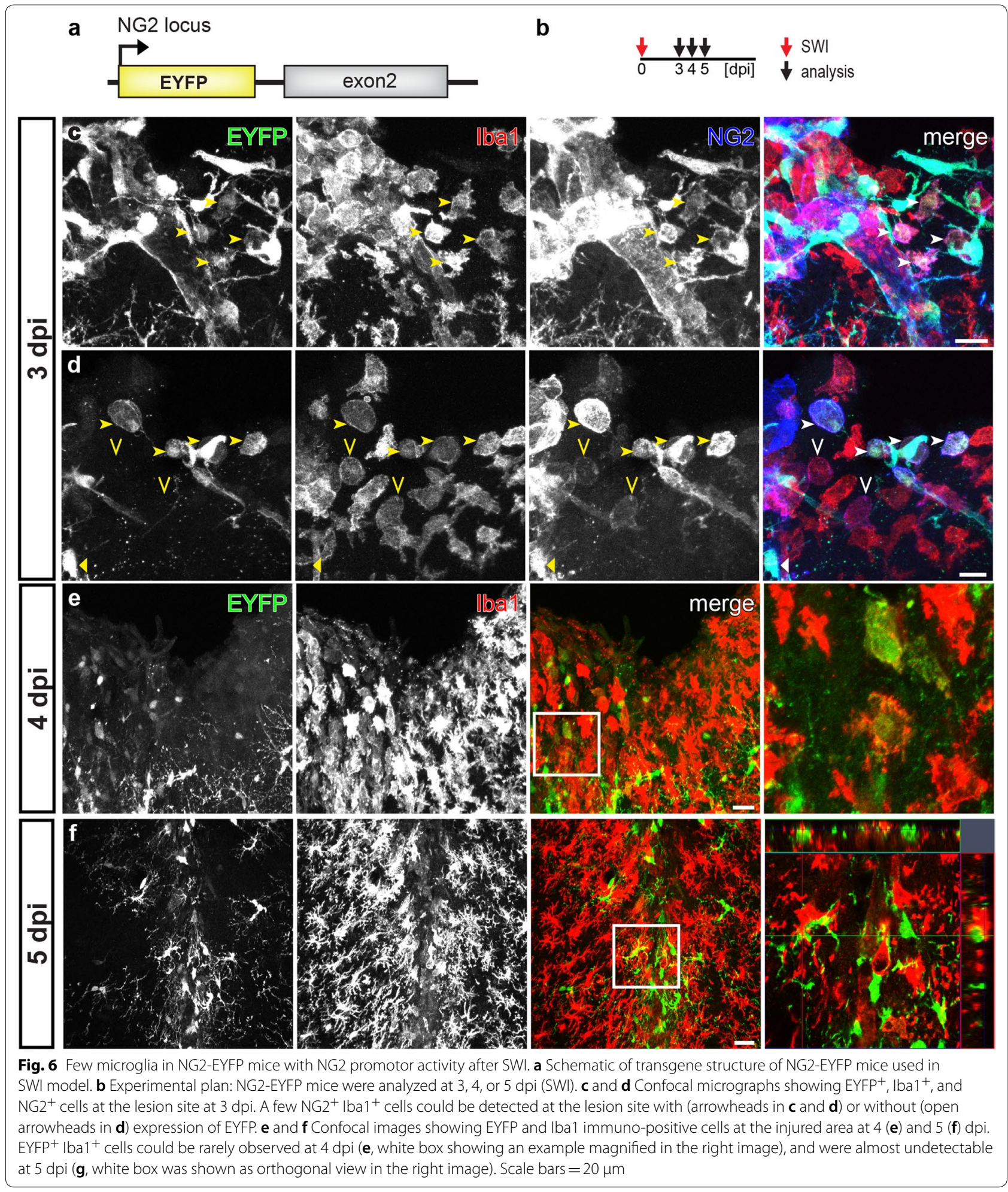

in line with previous studies demonstrating that NG2 glia/ OPCs did not generate microglia, as well as a recent study using Tbx18-CreERT2 mice showing that pericytes did not behave as stem cells to differentiate into other cells types in a variety of disease models including SWI [16, 42]. Notably, some studies suggested that pericytes might give rise 
to microglia after injury. For example, RGS5 (regulator of G-protein signaling 5) is another marker of pericytes. In a permanent MCAO stroke model using RGS5-GFP mice $\mathrm{GFP}^{+}$cells were immuno-positive for microglial markers [46]. However, microglia were reported to transiently express non-microglial genes upon activation [53], therefore, it was possible that the RGS-5 promoter was somehow induced in microglia after stroke, enabling the GFP expression. On the other hand, we cannot rule out that differences of disease models triggered pericytes to behave differently. Nevertheless, our current results showing NG2-expressing cells did not generate microglia further confirmed that $\mathrm{tdT}^{+} \mathrm{EGFP}^{+}$cells being detected when Cre activity was induced after injuries were indeed due to the activation of the NG2 gene in a subset of microglia.

Transient MCAO induced long-lasting brain damage, while after cortical SWI the wound healed quickly with reduced glia activation [12, 20, 35, 39]. With $\mathrm{NG}^{\mathrm{tdT}} \mathrm{xCXCR}^{\mathrm{EGFP}}$ mice, we were able to show that the generation and the time frame of appearance of NG2expressing microglia also differed in those two injury models by inducing Cre activity at different time points. In tMCAO, a small population of $\mathrm{EGFP}^{+}$microglia continuously activated the NG2 gene in terms of tdT expression at least in the first post-lesion week, whereas microglial NG2 gene activity could only be detected at the lesion site shortly after SWI. In addition, we observed more $\mathrm{td}^{+} \mathrm{EGFP}^{+}$cells when $\mathrm{NG}^{\mathrm{tdT}} \mathrm{xCXCR^{ \textrm {EGFP } }}$ mice were treated with tamoxifen at 2-4 days post $\mathrm{tMCAO}$, coincident with previous studies demonstrating the MCAO-induced damage developed progressively to reach the peak at 2-3 dpi $[20,35]$. Therefore, the present results suggest that microglial NG2 gene activation is dependent on the type and severity of injury.

Our immunohistochemical experiments detected a subset of $\mathrm{tdT}^{+} \mathrm{EGFP}^{+}$cells with NG2 immunoreactivity in both injury models, strongly suggesting that those cells also express NG2 protein. After SWI, the detectable NG2 immunoreactivity in microglia in $\mathrm{NG}^{\mathrm{tdT}} \mathrm{xCXCR}^{\mathrm{EGFP}}$ mice or in NG2-EYFP mice all showed up within the first 3 days, generally consistent with the NG2 gene activity revealed by reporter gene expression. However, in $\mathrm{NG}^{\mathrm{tdT}} \mathrm{xCXCR^{ \textrm {EGFP } }}$ mice we also found some $\mathrm{tdT}^{+} \mathrm{EGFP}^{+}$cells without NG2 immunoreactivity in the tMCAO model which triggered continuous activation of NG2 gene as well as at 3 dpi in the SWI model. Because Cre mediated recombination generated permanent tdT expression, those observations of NG2 immuno-negative $\mathrm{tdT}^{+} \mathrm{EGFP}^{+}$cells could be interpreted in such way, that the NG2 protein had been already degraded. On the other hand, it has been reported that some cortical neurons in the postnatal brain could acquire slight NG2 gene activity leading to the reporter recombination in
NG2-CreERT2xRosa26-tdT mice, but without inducing the expression of NG2 protein [24]. Therefore, we could also conceive that some microglia possessed moderate NG2 gene activity after injury which enabled only the expression of Cre rather than endogenous NG2 protein. Nevertheless, although the dynamic regulation of NG2 protein in microglia remains to be elucidated, our current results provide strong evidence that microglia are one of the sources of NG2 protein after acute brain injuries.

Although we observed significant numbers of $\mathrm{tdT}^{+} \mathrm{EGFP}^{+}$ cells in our tMCAO model, the number of $\mathrm{tdT}^{+} \mathrm{EGFP}^{+}$cells was still lower than numbers of $\mathrm{NG}^{+}$microglia found in previous studies in rat $(\sim 60 \%)[38,55]$. The brain damage increased with the occlusion period in the tMCAO model, which might account for the discrepancy detected in those studies (15 and $90 \mathrm{~min}$ in the present and previous studies, respectively) $[38,55]$. Of note, in SWI models the number of $\mathrm{tdT}^{+} \mathrm{EGFP}^{+}$cells found in the present mouse study was also much lower than the number of microglia with NG2 immunoreactivity found in rat (at least 20\%) [17,60]. Therefore, we cannot rule out that the species difference regarding NG2 gene activity contributed to the discrepancy among those studies as well. The biological significance of the NG2 proteoglycan generated from microglia in our models remains to be determined. Further experiments combining NG2 floxed mice [8] and microglia-Cre expressing mice (such as $\mathrm{CX}_{3} \mathrm{CR}_{1}$-Cre [61]), however, will facilitate the study of functions of the NG2 expressed by microglia.

The NG2 immunoreactivity in microglia is not restricted to tMCAO and SWI, as it was studied by us, it was also reported in other rodent models of CNS trauma such as spinal cord injury (SCI) or LPS-induced inflammation [25, 62]. Moreover, several studies suggest that the NG2 proteoglycan is involved in axon growth and inflammatory response $[21,32,56]$, and transplantation of $\mathrm{NG}^{+}$microglia ameliorated ischemic damage in rat brain [52]. On the other hand, previous immunohistochemical studies in human specimen suggested a similar NG2 expression pattern as in rodents. For example, NG2 could be detected in OPCs and pericytes in the healthy human $\mathrm{CNS}$ and was also found upregulated under pathological conditions [4, 54]. Furthermore, NG2 was immunodetectable in microglia/macrophages in samples from patients who encountered acute CNS injuries such as SCI or stroke, though the functions were not determined [7, 52]. Therefore, combined with other techniques such as genetic cell ablation [15], NG2 $2^{\mathrm{tdT}} x C X C R^{\mathrm{EGFP}}$ mice would be a valuable tool for the mechanistic study of the generation and function of NG2-expressing microglia, as well as the contribution of NG2 derived from distinct cell populations in different diseases. 


\section{Supplementary information}

Supplementary information accompanies this paper at https://doi. org/10.1186/s40478-020-01016-2.

Additional file 1: Supplementary Figure S1. Assessment of infarctaffected area in the brain. Supplementary Figure S2. After SWI tdT ${ }^{+}$ $\mathrm{EGFP}^{+}$cells were not derived from spontaneous recombination or pre-existing NG2-expressing cells. Supplementary Figure S3. Microglial phagocytosis of dying $\mathrm{tdT}^{+}$cells.

\section{Abbreviations}

CNS: Central nervous system; dpi: Days post injury; EAE: Experimental autoimmune encephalomyelitis; NG2: Nerve/glia antigen-2; OPC: Oligodendrocyte precursor cell; Rosa26-tdT: Rosa26Actin ${ }^{f l}$ STOPfl tdTomato; SWI: Stab wound injury; tam: Tamoxifen; tdT: tdTomato; tMCAO: Transient middle cerebral artery occlusion.

\section{Acknowledgements}

The authors are grateful to Prof. Dr. Frank Kirchhoff for his generous support and comments on the manuscript, to Frank Rhode for excellent technical assistance and to Daniel Rhode and all animal caretakers of the CIPMM for animal husbandry and tamoxifen treatment. We thank Dr. Hongkui Zeng (Allen Institute for Brain Science, Seattle, Washington, USA) for providing Rosa26-tdTomato reporter mice, and Prof. Dr. Jacqueline Trotter (Molecular Cell Biology, Johannes-Gutenberg University, Mainz, Germany) for providing NG2-EYFP knockin mice and AN2/NG2 antibodies.

\section{Authors' contributions}

$\mathrm{WH}$ and $\mathrm{AS}$ conceived and designed the experiments and wrote the manuscript with input from XB and EM. WH performed slice preparation, immunohistochemistry, confocal imaging and data analysis. XB and EM performed SWI and tMCAO surgeries, respectively. AS performed the AxioScan and confocal imaging. All authors read and approved the final manuscript.

\section{Funding}

Open access funding provided by Projekt DEAL. This work was supported by grants from the Deutsche Forschungsgemeinschaft DFG Sino-German joint project (KI 503/14-1) to WH, DFG FOR 2289 to AS; from the Saarland University Medical Faculty HOMFOR2015, HOMFORexzellenz2016 and HOMFORexzellenz2017 to AS, WH and XB, respectively. EM was support by the Coordenação de Aperfeiçoamento de Pessoal de Nível Superior - Brasil (CAPES) - PDSE Edital n०41/2018. AS and EM were also supported by CAPES/DAAD/PROBRAL grant for the project 57447150: Neuron-glia interaction in chronic degenerative pathologies of the CNS. WH was also supported by DFG SFB 894 and the European Commission EC-H2020 FET ProAct Neurofibres EC-H2020 FET ProAct Neurofibres.

\section{Competing interests}

The authors declare that they have no competing interests.

\section{Author details}

${ }^{1}$ Molecular Physiology, Center for Integrative Physiology and Molecular Medicine, University of Saarland, Building 48, 66421 Homburg, Germany. ${ }^{2}$ Laboratory of Brain Ischemia and Neuroprotection, Department of Pharmacology and Therapeutics, State University of Maringá, Maringá CEP-87020900, Brazil.

Received: 19 June 2020 Accepted: 10 August 2020

Published online: 26 August 2020

\section{References}

1. Adams KL, Gallo V (2018) The diversity and disparity of the glial scar. Nat Neurosci 21:9-15. https://doi.org/10.1038/s41593-017-0033-9

2. Bai X, Saab AS, Huang W, Hoberg IK, Kirchhoff F, Scheller A (2013) Genetic background affects human glial fibrillary acidic protein promoter activity. PLoS ONE 8:e66873. https://doi.org/10.1371/journal.pone.0066873
3. Baror R, Neumann B, Segel M, Chalut KJ, Fancy SPJ, Schafer DP, Franklin RJM (2019) Transforming growth factor-beta renders ageing microglia inhibitory to oligodendrocyte generation by CNS progenitors. Glia 67:1374-1384. https://doi.org/10.1002/glia.23612

4. Bedner P, Jabs R, Steinhäuser C (2020) Properties of human astrocytes and NG2 glia. Glia 68:756-767. https://doi.org/10.1002/glia.23725

5. Bradl M, Bauer J, Inomata T, Zielasek J, Nave KA, Toyka K, Lassmann H, Wekerle H (1999) Transgenic Lewis rats overexpressing the proteolipid protein gene: myelin degeneration and its effect on T cell-mediated experimental autoimmune encephalomyelitis. Acta Neuropathol 97:595-606. https://doi.org/10.1007/s004010051035

6. Bu J, Akhtar N, Nishiyama A (2001) Transient expression of the NG2 proteoglycan by a subpopulation of activated macrophages in an excitotoxic hippocampal lesion. Glia 34:296-310

7. Buss A, Pech K, Kakulas BA, Martin D, Schoenen J, Noth J, Brook GA (2009) NG2 and phosphacan are present in the astroglial scar after human traumatic spinal cord injury. BMC Neurol 9:32. https://doi. org/10.1186/1471-2377-9-32

8. Chang Y, She ZG, Sakimura K, Roberts A, Kucharova K, Rowitch DH, Stallcup WB (2012) Ablation of NG2 proteoglycan leads to deficits in brown fat function and to adult onset obesity. PLOS ONE 7:e30637. https://doi. org/10.1371/journal.pone.0030637

9. Corish P, Tyler-Smith C (1999) Attenuation of green fluorescent protein half-life in mammalian cells. Protein Eng 12:1035-1040. https://doi. org/10.1093/protein/12.12.1035

10. Dawson MR, Polito A, Levine JM, Reynolds R (2003) NG2-expressing glial progenitor cells: an abundant and widespread population of cycling cells in the adult rat CNS. Mol Cell Neurosci 24:476-488

11. Diers-Fenger M, Kirchhoff F, Kettenmann H, Levine JM, Trotter J (2001) AN2/NG2 protein-expressing glial progenitor cells in the murine CNS: isolation, differentiation, and association with radial glia. Glia 34:213-228

12. Frik J, Merl-Pham J, Plesnila N, Mattugini N, Kjell J, Kraska J, Gómez RM, Hauck SM, Sirko S, Götz M (2018) Cross-talk between monocyte invasion and astrocyte proliferation regulates scarring in brain injury. EMBO Rep. https://doi.org/10.15252/embr.201745294

13. Galloway DA, Blandford SN, Berry T, Williams JB, Stefanelli M, Ploughman M, Moore CS (2019) miR-223 promotes regenerative myeloid cell phenotype and function in the demyelinated central nervous system. Glia 67:857-869. https://doi.org/10.1002/glia.23576

14. Garcia-Bonilla L, Faraco G, Moore J, Murphy M, Racchumi G, Srinivasan J, Brea D, ladecola C, Anrather J (2016) Spatio-temporal profile, phenotypic diversity, and fate of recruited monocytes into the post-ischemic brain. J Neuroinflamm 13:285. https://doi.org/10.1186/s12974-016-0750-0

15. Grégoire D, Kmita M (2014) Genetic cell ablation. Methods Mol Biol 1092:421-436. https://doi.org/10.1007/978-1-60327-292-6_25

16. Guimarães-Camboa N, Cattaneo P, Sun Y, Moore-Morris T, Gu Y, Dalton ND Rockenstein E, Masliah E, Peterson KL, Stallcup WB et al (2017) Pericytes of multiple organs do not behave as mesenchymal stem cells in vivo. Cell Stem Cell 20:345-359.e345. https://doi.org/10.1016/j.stem.2016.12.006

17. Hampton DW, Asher RA, Kondo T, Steeves JD, Ramer MS, Fawcett JW (2007) A potential role for bone morphogenetic protein signalling in glial cell fate determination following adult central nervous system injury in vivo. Eur J Neurosci 26:3024-3035. https://doi.org/10.111 1/j.1460-9568.2007.05940.x

18. Hampton DW, Rhodes KE, Zhao C, Franklin RJ, Fawcett JW (2004) The responses of oligodendrocyte precursor cells, astrocytes and microglia to a cortical stab injury, in the brain. Neuroscience 127:813-820. https://doi. org/10.1016/j.neuroscience.2004.05.028

19. Hirrlinger PG, Scheller A, Braun C, Hirrlinger J, Kirchhoff F (2006) Temporal control of gene recombination in astrocytes by transgenic expression of the tamoxifen-inducible DNA recombinase variant CreERT2. Glia 54:11-20. https://doi.org/10.1002/glia.20342

20. Hirt L, Fukuda AM, Ambadipudi K, Rashid F, Binder D, Verkman A, Ashwal S, Obenaus A, Badaut J (2017) Improved long-term outcome after transient cerebral ischemia in aquaporin-4 knockout mice. J Cereb Blood Flow Metab 37:277-290. https://doi.org/10.1177/0271678X15623290

21. Huang C, Sakry D, Menzel L, Dangel L, Sebastiani A, Krämer T, Karram K, Engelhard K, Trotter J, Schäfer MK (2016) Lack of NG2 exacerbates neurological outcome and modulates glial responses after traumatic brain injury. Glia 64:507-523. https://doi.org/10.1002/glia.22944 
22. Huang W, Bai X, Stopper L, Catalin B, Cartarozzi LP, Scheller A, Kirchhoff F (2018) During development NG2 glial cells of the spinal cord are restricted to the oligodendrocyte lineage, but generate astrocytes upon acute injury. Neuroscience 385:154-165. https://doi.org/10.1016/j.neuro science.2018.06.015

23. Huang W, Guo Q, Bai X, Scheller A, Kirchhoff F (2019) Early embryonic NG2 glia are exclusively gliogenic and do not generate neurons in the brain. Glia 67:1094-1103. https://doi.org/10.1002/glia.23590

24. Huang W, Zhao N, Bai X, Karram K, Trotter J, Goebbels S, Scheller A, Kirchhoff F (2014) Novel NG2-CreERT2 knock-in mice demonstrate heterogeneous differentiation potential of NG2 glia during development. Glia 62:896-913. https://doi.org/10.1002/glia.22648

25. Jones LL, Yamaguchi Y, Stallcup WB, Tuszynski MH (2002) NG2 is a major chondroitin sulfate proteoglycan produced after spinal cord injury and is expressed by macrophages and oligodendrocyte progenitors. J Neurosci 22:2792-2803. https://doi.org/10.1523/JNEUROSCI.2207-02792.2002

26. Jung B, Arnold TD, Raschperger E, Gaengel K, Betsholtz C (2018) Visualization of vascular mural cells in developing brain using genetically labeled transgenic reporter mice. J Cereb Blood Flow Metab 38:456-468. https://doi.org/10.1177/0271678X17697720

27. Jung S, Aliberti J, Graemmel P, Sunshine MJ, Kreutzberg GW, Sher A, Littman DR (2000) Analysis of fractalkine receptor CX(3)CR1 function by targeted deletion and green fluorescent protein reporter gene insertion. Mol Cell Biol 20:4106-4114

28. Karram K, Goebbels S, Schwab M, Jennissen K, Seifert G, Steinhäuser C, Nave KA, Trotter J (2008) NG2-expressing cells in the nervous system revealed by the NG2-EYFP-knockin mouse. Genesis 46:743-757. https ://doi.org/10.1002/dvg.20440

29. Kettenmann H, Hanisch UK, Noda M, Verkhratsky A (2011) Physiology of microglia. Physiol Rev 91:461-553. https://doi.org/10.1152/physr ev.00011.2010

30. Kitic M, Karram K, Israel N, Yogev N, Lacher SM, Tang Y, Yigit H, Bauer J, Wanke F, Knezovic A et al (2017) NG2 plays a role in neuroinflammation but is not expressed by immune cells. Acta Neuropathol 134:325-327. https://doi.org/10.1007/s00401-017-1735-5

31. Koizumi J-i, Yoshida Y, Nakazawa T, Ooneda G (1986) Experimental studies of ischemic brain edema 1. A new experimental model of cerebral embolism in rats in which recirculation can be introduced in the ischemic area. Jpn J Stroke 8:1-8. https://doi.org/10.3995/jstroke.8.1

32. Kucharova K, Chang Y, Boor A, Yong VW, Stallcup WB (2011) Reduced inflammation accompanies diminished myelin damage and repair in the NG2 null mouse spinal cord. J Neuroinflammation 8:158. https:// doi.org/10.1186/1742-2094-8-158

33. Kucharova K, Stallcup WB (2015) NG2-proteoglycan-dependent contributions of oligodendrocyte progenitors and myeloid cells to myelin damage and repair. J Neuroinflamm 12:161. https://doi.org/10.1186/ s12974-015-0385-6

34. Li T, Pang S, Yu Y, Wu X, Guo J, Zhang S (2013) Proliferation of parenchymal microglia is the main source of microgliosis after ischaemic stroke. Brain 136:3578-3588. https://doi.org/10.1093/brain/awt287

35. Liu F, McCullough LD (2011) Middle cerebral artery occlusion model in rodents: methods and potential pitfalls. J Biomed Biotechnol 2011:464701. https://doi.org/10.1155/2011/464701

36. Madisen L, Mao T, Koch H, Zhuo J, Berenyi A, Fujisawa S, Hsu Y, Garcia A, Gu X, Zanella S et al (2012) A toolbox of Cre-dependent optogenetic transgenic mice for light-induced activation and silencing. Nat Neurosci 15:793-802. https://doi.org/10.1038/nn.3078

37. Madisen L, Zwingman TA, Sunkin SM, Oh SW, Zariwala HA, Gu H, Ng LL, Palmiter RD, Hawrylycz MJ, Jones AR et al (2010) A robust and high-throughput Cre reporting and characterization system for the whole mouse brain. Nat Neurosci 13:133-140. https://doi.org/10.1038/ $\mathrm{nn} .2467$

38. Matsumoto H, Kumon Y, Watanabe H, Ohnishi T, Shudou M, Chuai M, Imai Y, Takahashi H, Tanaka J (2008) Accumulation of macrophage-like cells expressing NG2 proteoglycan and Iba1 in ischemic core of rat brain after transient middle cerebral artery occlusion. J Cereb Blood Flow Metab 28:149-163. https://doi.org/10.1038/sj.jcbfm.9600519

39. Mattugini N, Merl-Pham J, Petrozziello E, Schindler L, Bernhagen J, Hauck SM, Götz M (2018) Influence of white matter injury on gray matter reactive gliosis upon stab wound in the adult murine cerebral cortex. Glia 66:1644-1662. https://doi.org/10.1002/glia.23329

40. Moransard M, Dann A, Staszewski O, Fontana A, Prinz M, Suter T (2011) NG2 expressed by macrophages and oligodendrocyte precursor cells is dispensable in experimental autoimmune encephalomyelitis. Brain 134:1315-1330. https://doi.org/10.1093/brain/awr070

41. Niehaus A, Stegmüller J, Diers-Fenger M, Trotter J (1999) Cell-surface glycoprotein of oligodendrocyte progenitors involved in migration. J Neurosci 19:4948-4961

42. Nishiyama A, Boshans L, Goncalves CM, Wegrzyn J, Patel KD (2016) Lineage, fate, and fate potential of NG2-glia. Brain Res 1638:116-128. https://doi.org/10.1016/j.brainres.2015.08.013

43. Nishiyama A, Komitova M, Suzuki R, Zhu X (2009) Polydendrocytes (NG2 cells): multifunctional cells with lineage plasticity. Nat Rev Neurosci 10:9-22. https://doi.org/10.1038/nrn2495

44. Nishiyama A, Lin XH, Giese N, Heldin CH, Stallcup WB (1996) Colocalization of NG2 proteoglycan and PDGF alpha-receptor on O2A progenitor cells in the developing rat brain. J Neurosci Res 43:299-314. https://doi.org/10.1002/(SICl)1097-4547(19960201)43:3\%3c299 :AID-JNR5\%3e3.0.CO;2-E

45. Nishiyama A, Yu M, Drazba JA, Tuohy VK (1997) Normal and reactive $\mathrm{NG} 2^{+}$glial cells are distinct from resting and activated microglia. J Neurosci Res 48:299-312. https://doi.org/10.1002/(sici)10974547(19970515)48:4\%3c299:aid-jnr2\%3e3.0.co;2-6

46. Özen I, Deierborg T, Miharada K, Padel T, Englund E, Genové G, Paul G (2014) Brain pericytes acquire a microglial phenotype after stroke. Acta Neuropathol 128:381-396. https://doi.org/10.1007/s00401-014-1295-x

47. Ozerdem U, Grako KA, Dahlin-Huppe K, Monosov E, Stallcup WB (2001) NG2 proteoglycan is expressed exclusively by mural cells during vascular morphogenesis. Dev Dyn 222:218-227. https://doi.org/10.1002/ dvdy. 1200

48. Pedrono E, Durukan A, Strbian D, Marinkovic I, Shekhar S, Pitkonen M, Abo-Ramadan U, Tatlisumak T (2010) An optimized mouse model for transient ischemic attack. J Neuropathol Exp Neurol 69:188-195. https ://doi.org/10.1097/NEN.0b013e3181cd331c

49. Rivers LE, Young KM, Rizzi M, Jamen F, Psachoulia K, Wade A, Kessaris N, Richardson WD (2008) PDGFRA/NG2 glia generate myelinating oligodendrocytes and piriform projection neurons in adult mice. Nat Neurosci 11:1392-1401. https://doi.org/10.1038/nn.2220

50. Safaiyan S, Kannaiyan N, Snaidero N, Brioschi S, Biber K, Yona S, Edinger AL, Jung S, Rossner MJ, Simons M (2016) Age-related myelin degradation burdens the clearance function of microglia during aging. Nat Neurosci 19:995-998. https://doi.org/10.1038/nn.4325

51. Schäfer MKE, Tegeder I (2018) NG2/CSPG4 and progranulin in the posttraumatic glial scar. Matrix Biol 68-69:571-588. https://doi. org/10.1016/j.matbio.2017.10.002

52. Smirkin A, Matsumoto H, Takahashi H, Inoue A, Tagawa M, Ohue S, Watanabe H, Yano H, Kumon Y, Ohnishi T et al (2010) Iba1(+)/NG2(+) macrophage-like cells expressing a variety of neuroprotective factors ameliorate ischemic damage of the brain. J Cereb Blood Flow Metab 30:603-615. https://doi.org/10.1038/jcbfm.2009.233

53. Solga AC, Pong WW, Walker J, Wylie T, Magrini V, Apicelli AJ, Griffith M, Griffith OL, Kohsaka S, Wu GF et al (2015) RNA-sequencing reveals oligodendrocyte and neuronal transcripts in microglia relevant to central nervous system disease. Glia 63:531-548. https://doi.org/10.1002/ glia.22754

54. Staugaitis SM, Trapp BD (2009) NG2-positive glia in the human central nervous system. Neuron Glia Biol 5:35-44. https://doi.org/10.1017/ S1740925X09990342

55. Sugimoto K, Nishioka R, Ikeda A, Mise A, Takahashi H, Yano H, Kumon Y, Ohnishi T, Tanaka J (2014) Activated microglia in a rat stroke model express NG2 proteoglycan in peri-infarct tissue through the involvement of TGF- $\beta 1$. Glia 62:185-198. https://doi.org/10.1002/glia.22598

56. Tan AM, Colletti M, Rorai AT, Skene JH, Levine JM (2006) Antibodies against the NG2 proteoglycan promote the regeneration of sensory axons within the dorsal columns of the spinal cord. J Neurosci 26:4729-4739. https://doi.org/10.1523/JNEUROSCI.3900-05.2006

57. Trotter J, Karram K, Nishiyama A (2010) NG2 cells: properties, progeny and origin. Brain Res Rev 63:72-82. https://doi.org/10.1016/j.brainresre v.2009.12.006 
58. Wang X, Cao K, Sun X, Chen Y, Duan Z, Sun L, Guo L, Bai P, Sun D, Fan J et al (2015) Macrophages in spinal cord injury: phenotypic and functional change from exposure to myelin debris. Glia 63:635-651. https:// doi.org/10.1002/glia.22774

59. Xiang $P$, Zhu L, Jiang H, He BP (2015) The activation of NG2 expressing cells is downstream to microglial reaction and mediated by the transforming growth factor beta 1. J Neuroimmunol 279:50-63. https://doi. org/10.1016/j.jneuroim.2015.01.006

60. Yokoyama A, Sakamoto A, Kameda K, Imai Y, Tanaka J (2006) NG2 proteoglycan-expressing microglia as multipotent neural progenitors in normal and pathologic brains. Glia 53:754-768. https://doi. org/10.1002/glia.20332

61. Yona S, Kim KW, Wolf Y, Mildner A, Varol D, Breker M, Strauss-Ayali D, Viukov S, Guilliams M, Misharin A et al (2013) Fate mapping reveals origins and dynamics of monocytes and tissue macrophages under homeostasis. Immunity 38:79-91. https://doi.org/10.1016/j.immun i.2012.12.001

62. Zhu L, Xiang P, Guo K, Wang A, Lu J, Tay SS, Jiang H, He BP (2012) Microglia/monocytes with NG2 expression have no phagocytic function in the cortex after LPS focal injection into the rat brain. Glia 60:1417-1426. https ://doi.org/10.1002/glia.22362

\section{Publisher's Note}

Springer Nature remains neutral with regard to jurisdictional claims in published maps and institutional affiliations.
Ready to submit your research? Choose BMC and benefit from:

- fast, convenient online submission

- thorough peer review by experienced researchers in your field

- rapid publication on acceptance

- support for research data, including large and complex data types

- gold Open Access which fosters wider collaboration and increased citations

- maximum visibility for your research: over $100 \mathrm{M}$ website views per year

At BMC, research is always in progress.

Learn more biomedcentral.com/submissions 